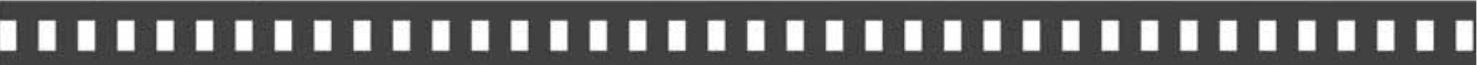

\section{Cartoon Movement: colaboração, independência e diversidade}

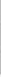

Ana Cláudia Gruszynski

Ariel Lara de Oliveira

Artigo recebido em: 27/09/2015

Artigo aprovado em: 23/11/2015

DOI 10.5433/1984-7939.2015v11n19p11 


\title{
Cartoon Movement: colaboração, independência e diversidade
}

\author{
Cartoon Movement: cooperation, \\ independence and diversity
}

\author{
Ana Cláudia Gruszynski * \\ Ariel Lara de Oliveira**
}

\begin{abstract}
Resumo: $O$ artigo apresenta parte dos resultados de dissertação de mestrado que identificou e analisou elementos que caracterizam o jornalismo em quadrinhos na web em suas dimensões editorial, institucional e comercial, a partir da experiência do site Cartoon Movement (CM). O foco incide em três aspectos identificados nas falas institucionais do CM: a produção colaborativa, a independência editorial e a diversidade de vozes. Por meio da análise descritiva e exploratória do site, conclui-se que este incorpora recursos tanto do jornalismo digital quando dos webcomics, constituindo-se como uma proposta nativa digital que, por meio da estrutura comercial adotada, viabiliza que o conteúdo editorial reflita os valores institucionais do CM.
\end{abstract}

Palavras-chave: Jornalismo em Quadrinhos. Webcomics. Jornalismo digital. Cartum.

\begin{abstract}
The article presents part of the dissertation results that identified and analyzed characteristics of a comics journalism website in its editorial, institutional and commercial dimensions, from the Cartoon Movement (CM) site experience. It focuses on three aspects present in CM institutional speeches: collaborative production, editorial independence and diversity of voices. Through the descriptive and exploratory analysis, it is concluded that CM incorporates features of digital journalism and webcomics. As a digital native proposal, is the business structure adopted that enables the editorial content to reflect the institutional values of $C M$.
\end{abstract}

Keywords: Comics Journalism. Webcomics.

Digital Journalism. Cartoon.

* Professora do Programa de Pós-graduação em Comunicação e Informação da Universidade Federal do Rio Grande do Sul. Pesquisadora do CNPq. Coordenadora do Laboratório de Edição, Cultura e Design (LEAD).

** Jornalista. Mestre pelo Programa de Pós-graduação em Comunicação e Informação da Universidade Federal do Rio Grande do Sul. 


\section{Introdução}

O jornalismo em quadrinhos, forma relativamente recente de fazer jornalismo, conheceu uma grande expansão na internet, graças à maior facilidade de produção e publicação possibilitada no meio digital e em rede. Se, por um lado, mostra características do jornalismo em quadrinhos impresso, por outro apresenta também características do jornalismo digital e dos webcomics.

Apresentamos aqui parte de resultados de dissertação que identificou e analisou elementos que caracterizam o jornalismo em quadrinhos na web em suas dimensões editorial, institucional e comercial, a partir da experiência do site Cartoon Movement ${ }^{1}$ (CM). Adotamos como foco três aspectos presentes nas falas institucionais do CM: a produção colaborativa, a independência editorial e a diversidade de vozes, avaliando como estas se articulam para a sustentação da proposta de edição empreendida pelo site. Em um primeiro momentos introduzimos princípios que orientaram a avaliação de nosso objeto, para a seguir nos determos na apresentação e análise dos dados.

\section{O jornalismo em quadrinhos na internet}

O jornalismo digital pode ser sistematizado em cinco fases ou gerações. A primeira geração, fase da transposição, corresponde à digitalização do conteúdo impresso e disponibilização deste na web; a segunda, da metáfora, seria a da produção de conteúdo original para a web, com uso de hipertexto, mas ainda fortemente atrelado à ideia da página física do jornal; a terceira geração corresponde ao webjornalismo propriamente dito, quando começa a utilização de recursos próprios do suporte digital, como multimídia, interatividade, personalização, hipertexto, memória e

http://www.cartoonmovement.com/ 
instantaneidade de publicação de conteúdo atualizado (PALACIOS, 2002; MIELNICZUK, 2003). A quarta geração é a que se baseia no paradigma do banco de dados (surgido em uma etapa de transição entre as duas fases) e compreende o jornalismo colaborativo, além de possibilidades de cus-tomização do conteúdo (BARBOSA, 2008, PALÁCIOS e MACHADO, 2005); enquanto a quinta caracteriza-se pelo uso de mídias móveis como tablets e celulares, com conteúdo desenvolvido para (e disponibilizado através de) aplicativos específicos para esses dispositivos, marcada por um nível expressivo de replicação de conteúdos na distribuição multiplataforma (BARBOSA, 2013). Mielniczuk (2003, p. 31) reforça que essas fases podem existir tanto ao mesmo tempo como em uma mesma publicação, ou seja, "podemos encontrar publicações jornalísticas para a web que se enquadram em diferentes gerações e, em uma mesma publicação, pode-se encontrar aspectos que remetem a estágios distintos".

Os recursos do ambiente digital e em rede delineiam elementos que singularizam o jornalismo presente na internet, conforme indica Palácios (2002). Para o autor, a interatividade é a capacidade que a notícia online tem de fazer o leitor se sentir parte do processo jornalístico, através de e-mails, pesquisas de opinião, fóruns de discussão, chats. A multimidialidade consiste na convergência dos formatos mais tradicionais (imagem, texto e som) na narração do fato jornalístico. A hipertextualidade consiste na possibilidade de fazer interconexões de textos através de links para animações, fotos, sons, vídeos, outros sites relacionados ou material de arquivo de jornais (não mais apenas um recurso de organização, mas empregado na própria narrativa dos fatos). A customização compreende a opção do leitor configurar o produto jornalístico de acordo com suas preferências e interesses. Já memória é como o autor denomina a possibilidade (mais viável na web) de acumular informações e disponibilizá-las ao público, através de arquivamento e busca em bancos de dados; enquanto a instantaneidade se refere a facilidade e 
e rapidez de acesso, produção e disponibilização de novo conteúdo na internet.

Steensen (2010) destaca que a pesquisa de jornalismo digital focada em tecnologia aborda três evoluções que potencialmente causam o maior impacto na produção: hipertexto, interatividade e multimídia. Ele cita diversos autores que expandiram essa lista de características, mas defende que todos esses itens adicionais podem ser incluídos nesses três elementos essenciais. Para o autor, arquivo, contextualização, ubiquidade, transparência e memória são elementos que pertenceriam ao hipertexto, pois fazem parte de um "grupo não-linear e computadorizado de textos (escritos ou imagéticos) que são interligados por hyperlinks" (STEENSEN, 2010, p. 313). Aponta também que os estudos sobre hiperlinks em geral os classificam entre target links (links alvo, que direcionam para dentro do próprio texto), relative links (links internos, que direcionam para outras webpages no mesmo site) e external links (links externos, que direcionam para webpages em outros sites), sendo os relative links os mais comuns. $\mathrm{O}$ baixo uso de links externos faz sentido segundo uma estratégia de produção que leva em conta uma lógica protecionista, pois aumenta o número de views do site da empresa, o que traz mais publicidade, sem correr o risco de perder a atenção do leitor para outro site. O baixo uso de links alvo também se justifica, pois a maioria dos textos da grande mídia na internet ainda são muito curtos, não havendo a necessidade de navegação dentro de uma mesma matéria.

Enquanto o jornalismo digital já pode ser visto a partir das cinco gerações que apontamos, os quadrinhos digitais se configuram em três tipos principais: digitalizados, herdeiros e híbridos (MALLET, 2009), que se utilizam de elementos análogos aos das diferentes gerações do jornalismo digital vistas acima. Os quadrinhos digitalizados, por exemplo, corresponderiam à primeira fase: apresentam o mesmo conteúdo impresso disponibilizado pela web. Nessa categoria estão incluídas as digitalizações piratas (em 
formatos de arquivo que permitem a leitura seqüencial de imagens) e as traduções amadoras conhecidas por scanlation. Os quadrinhos herdeiros seriam correspondentes à segunda fase, da metáfora do impresso, pois, embora sejam constituídos de conteúdo originalmente produzido para a internet, ainda se mantêm presos a formatos dos quadrinhos impressos. Esses são, quantitativamente, o tipo mais comum de webcomics (SANTOS, 2010). Os quadrinhos híbridos, por sua vez, são os que rompem com paradigmas do impresso em favor da utilização de recursos dos meios digitais.

Quando começaram a ser criadas especificamente para a web, as histórias ainda se mantinham presas a conceitos dos quadrinhos impressos, particularmente a limitação de espaço. Em formato de página ou de tirinhas, os webcomics herdeiros costumam ser publicados em sites próprios, através de arquivos de imagem (SANTOS, 2010; ROMAGUERA, 2010; KOGEL, 2013). Santos (2010) nota ainda como diferentes formatos de arquivos de imagem podem possibilitar diferentes efeitos narrativos para os quadrinhos, especialmente as características de GIFs $^{2}$ (animações e pouco tamanho em menos de 250 cores) e JPGs $^{3}$ (compressão e pouco tamanho em aproximadamente 16 milhões de cores). Na maioria das vezes, são histórias serializadas publicadas periodicamente, cada hiperquadro ${ }^{4}$ aparecendo em uma webpage do site, com endereço próprio. Assim, permite-se o acesso a conteúdo antigo através de links para navegação (as guias first, previous, next, last, em geral aparecendo acima ou abaixo da imagem) e clicar em cada uma das guias leva a uma nova webpage, o que aumenta o número de visitas do site e gera mais receita publicitária. Além disso, se cada

2 Graphics Interchange Format, formato de imagem em bitmap que permite adicão de movimento em espaço compacto, além de ser suportado por vários softwares.

3 Joint Photographic Experts Groups, formato de imagem que permite uma boa proporção entre qualidade e tamanho do arquivo.

4 Hiperquadro é o espaço total de uma página de quadrinhos, a junção de todos os quadros daquele espaço narrativo. 
hiperquadro tem um $\mathrm{URL}^{5}$ diferente, o compartilhamento dela pelos usuários em fóruns e perfis de redes sociais é facilitado - e isso muitas vezes é incentivado pelos autores com botões específicos para se compartilhar cada imagem em blogs, Tumblr, Facebook, Twitter, Pinterest. A maioria dos sites de webcomics carrega a imagem mais recente da série diretamente na página inicial, deixando as mais antigas arquivadas. Com isso, se assemelham à estrutura de um blog, como "sites frequentemente atualizados, que consistem de entradas datadas, organizadas em ordem cronológica reversa, para que a postagem mais recente apareça primeiro" (RETTBERG apud KOGEL, 2013, p. 51).

Nos webcomics híbridos, começa-se a ter o uso de multimídia (inicialmente sons e animações, posteriormente vídeos, em geral embedados ${ }^{6}$ ), interatividade (desde seções de comentários, fóruns de discussão até a possibilidade de escolher entre duas ou mais ações do personagem) e hipertexto (links em quadros ou balões que levam para seções diferentes do quadrinho ou dão acesso a novo conteúdo) e, por isso mesmo, em geral necessitam de uma plataforma de leitura. Esses recursos são mais ou menos utilizados dependendo do tipo de quadrinho produzido (PAREDES, 2013; SANTOS, 2010). Os híbridos buscam uma identidade que se possa firmar na rede e por conta disso acabam sendo extremamente experimentais em sua apresentação formal, já que cada autor "propõe os seus ensaios (com animações, sons etc.) e, depois, separam [sic] o que acreditam [sic] ser mais adequado para suas narrativas, seja em termos de forma, seja em termos de viabilidade tecnológica" (MALLET, 2009, p. 84).

Nossa proposta de estudo, assim, parte do reconhecimento de princípios que orientam iniciativas no âmbito do jornalismo digital e do webcomics, para explorar se e como estas podem estar presentes

URL (de Uniform Resource Locator é o endereço de um recurso disponível em uma rede; tanto interna quando na Internet. A partir dele, pode-se localizar o que se quer a partir de um computador conectado a esta rede. Na internet, consiste no endereço do site na web, começando sempre por HTTP.

6 Do inglês, embed. É o conteúdo, em geral vídeos, por seu tamanho maior, reproduzido em um site a partir de outra fonte, de forma que não ocupe espaço no primeiro. 
em experiências de jornalismo em quadrinhos na Internet, a partir da avaliação do CM segundo o foco que estabelecemos.

\section{O Cartoon Movement}

O site Cartoon Movement é uma comunidade internacional de cartunistas e quadrinistas interessados em política e questões sociais. O CM se apresenta como uma plataforma online para cartuns políticos e jornalismo em quadrinhos. Fundado em 2010, com o objetivo de promover a liberdade de imprensa e os direitos de cartunistas políticos, atualmente conta com uma comunidade de mais de 280 profissionais vindos de 80 países diferentes. Sua seção de quadrinhos existe desde 2010, hospedando 36 reportagens no período de fechamento do corpus de análise da pesquisa empreendida. A seguir, por meio de uma avaliação descritiva e exploratória das principais seções do CM, vamos observar como se manifestam a produção colaborativa, a independência editorial e a diversidade de vozes.

Começaremos pela descrição da página inicial e posterior explicação dos aspectos institucionais que podem ser percebidos nela. No topo, à esquerda, encontra-se o logotipo do site, seguido de um slogan e, à direita dele, uma breve apresentação (Figura 1). Após, seguem-se links para acompanhar as atualizações de conteúdo nas redes sociais (Facebook, Twitter e RSS) e as seções Cartoonists, Webshop, About e Join, seguidas pelo link de login. Abaixo dessa linha, na aba principal, temos as seções Home, Newsroom, Cartoon, Comics, Projects, e, na sequência, mas separado, Blog e uma caixa para busca dentro do site. 
Figura 1: Página inicial Cartoon Movement (topo)

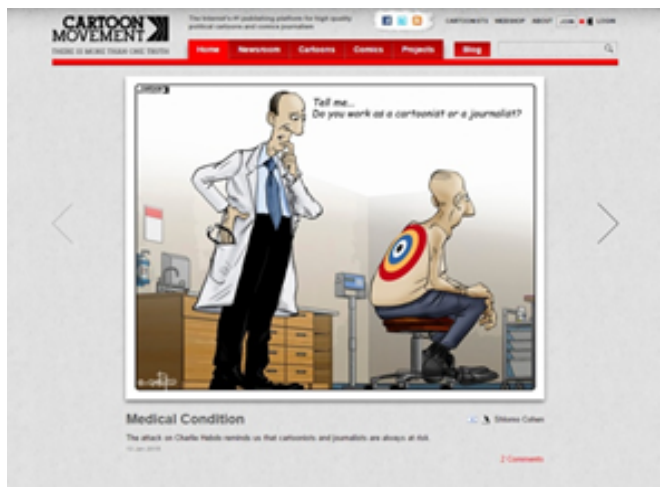

Fonte: http://www.cartoonmovement.com/

A aba principal, portanto, prioriza e destaca as seções do CM que apresentam conteúdo editorial, tanto os cartuns ou as reportagens em quadrinhos. Percebe-se também a importância das redes sociais no incentivo para o compartilhamento do conteúdo, aumentando a visualização do site, estratégia adotada por outros sites, tanto de jornalismo como de quadrinhos.

Esse cabeçalho básico é encontrado em todas as seções do CM exceto Blog e Webshop, que são sites separados, mantendo um design similar mas com outra estrutura. Logo abaixo, localiza-se a charge mais recente publicada na seção Cartoons, com flechas para a esquerda e direita, permitindo a navegação pelas próximas e anteriores, sem que se carregue uma nova URL, ou seja, não se perde o tempo de carregamento da imagem. Sob o cartum, há o título e uma breve descrição dele, um link para o perfil do autor no site, um ícone da bandeira de sua nacionalidade e um link para os comentários postados sobre aquele trabalho. A presença dos comentários na Home é indicativa da importância que o site dá à opinião e à participação do leitor; a preocupação com o feedback é importante na internet. Um espaço para comentários está disponível nas webpages de cada obra do site, seja cartum ou quadrinho, reforçando 
ainda mais esse conceito.

A partir desse ponto, o site se divide em três colunas (Figura 2). $\mathrm{Na}$ área imediatamente abaixo do cartum, a primeira coluna contém uma nova apresentação institucional; a segunda tem um link com imagem para a última seleção temática de cartuns; e a terceira apresenta um link para a última reportagem em quadrinhos publicada.

Figura 2: Página inicial Cartoon Movement (rolagem)

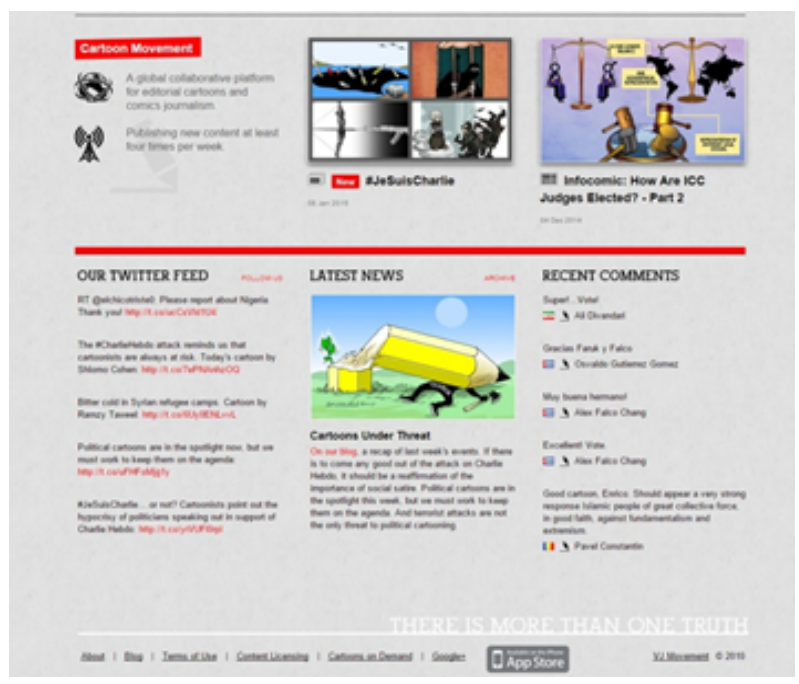

Fonte: http://www.cartoonmovement.com/

Na área seguinte, a primeira coluna apresenta o feed do Twitter do Cartoon Movement; a segunda, a última notícia publicada, com um link para a seção de notícias; e a terceira o feed dos últimos comentários postados no site. Novamente aqui temos duas características importantes: a ligação com o perfil do CM nas mídias sociais (o perfil no Twitter não apenas divulga conteúdo publicado, mas posta sugestões de leitura relacionadas à política editorial do veículo e interage com leitores e autores); e o incentivo a 
comentários dentro das plataformas internas do site específicas para isso (esse feed de comentários mostra os últimos comentários postados em qualquer parte do site, podendo ser sobre qualquer assunto; clicar no comentário leva para a webpage do cartum ou reportagem que foi comentado). Por último, há o rodapé, repetindo o slogan e trazendo links para as seções About, Blog, Terms of Use, Content Licensing e Cartoons on Demand, os dois últimos relacionados à manutenção financeira do site. Também no rodapé há links para o perfil do site no Google+, para o aplicativo na AppStore, e para o VJ Movement, comunidade de jornalistas independentes dentro da qual surgiu o CM.

A aba Home direciona para a página inicial. Acima, localiza-se o logotipo, de identidade sóbria e séria, refletindo a temática política e factual do CM. Ele se aproxima de logotipos de outros veículos jornalísticos, sendo bem diferente de logotipos de outros sites de webcomics. O slogan "There is more than one truth" ${ }^{7}$ " ajuda a estabelecer o site como um veículo alternativo e de muitas vozes. A descrição institucional "The Internet's \#1 publishing platform for high quality political cartoons and comics journalism ${ }^{8}$ " mostra que o CM não se identifica como um veículo produtor de conteúdo, mas como uma plataforma de publicação. A segunda apresentação, presente na parte inferior, informa: "A global collaborative platform for editorial cartoons and comics journalism. Publishing new content at least four times per week ${ }^{9}$ ", reforçando a ideia de plataforma e introduzindo a periodicidade. Essas descrições já estabelecem, também, os dois tipos de conteúdo publicados pelo CM: cartuns e quadrinhos.

Os cartuns aparecem principalmente em duas seções: Newsroom e Cartoons. A Newsroom (Figura 3) é a parte do CM que

Há mais de uma verdade, tradução nossa.

A plataforma número um na Internet para publicação de cartuns políticos e jornalismo em quadrinhos de alta qualidade, tradução nossa.

9 Uma plataforma colaborativa global para cartuns editoriais e jornalismo em quadrinhos. Publicando conteúdo novo pelo menos quatro vezes por semana, tradução nossa. 
funciona como uma rede social: é onde os usuários que têm perfis podem se comunicar e interagir.

Figura 3: Seção Newsroom

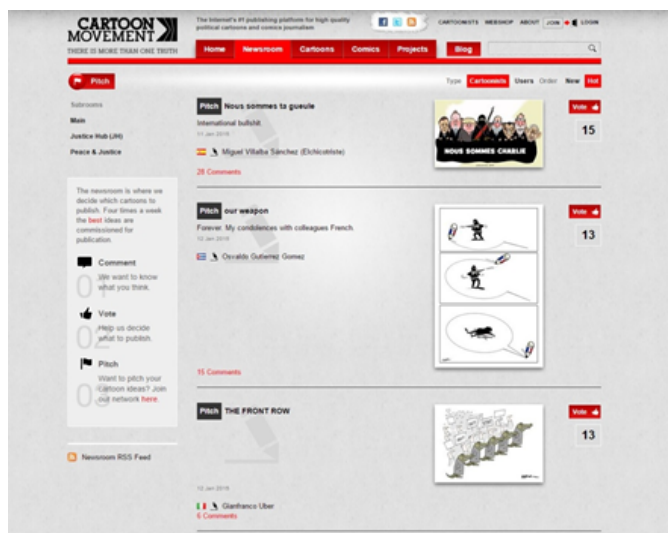

Fonte: http:/www.cartoonmovement.com/

Aqui são decididos quais cartuns serão publicados na seção Cartoons: quatro vezes por semana, as melhores ideias são escolhidas, levando em conta as opiniões dos editores e o voto dos usuários. Na Newsroom, os leitores interagem de três maneiras: votando em um cartum, comentando sobre ele ou dando sugestões para a produção de cartuns (cartuns produzidos a partir de sugestões ficam marcados com a tag Pitch). Pode-se ver a lista dos cartuns da equipe de cartunistas do site ou a dos enviados por usuários; os cartuns também podem ser vistos por ordem cronológica (New) ou de popularidade (Hot). Cada quadrinho sempre vem acompanhado do link para o perfil de seu autor, seja quadrinista ou usuário, junto com o ícone da bandeira de sua nacionalidade. O perfil possibilita acesso a mais conteúdo daquele autor e a bandeira serve para reforçar o aspecto internacional do site, importante na percepção institucional do veículo. Na Newsroom, há também diversas subseções, ligadas a temáticas específicas ou a algum dos vários projetos colaborativos de que o CM participa. 
Uma vez escolhido por editores e leitores, o cartum sai da Newsroom e é publicado em Cartoons (Figura 4), onde pode receber novos comentários, mas não há mais a possibilidade de voto ou sugestão.

Figura 4: Seção Cartoons

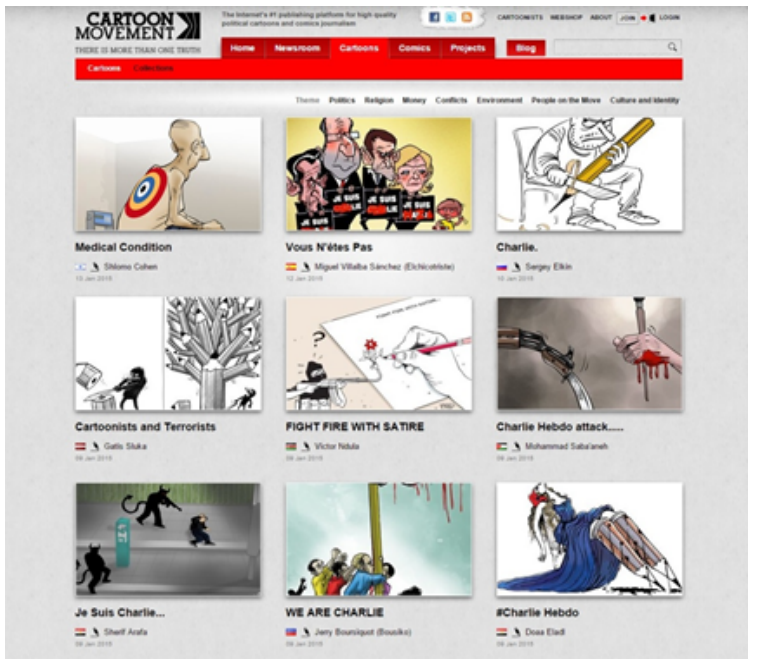

Fonte: http://www.cartoonmovement.com/

Essa seção apresenta os quadrinhos que o site efetivamente publica, dando origem ao suporte financeiro do Cartoon Movement. $\mathrm{O}$ último cartum daqui aparece com link na página inicial. Pode-se percorrer a lista geral ou as listas temáticas, expostas na parte de cima (Politics, Religion, Money, Conflicts, Environment, People on the Move, Culture and Identity). Clicando na aba Collections, pode-se acessar coletâneas de cartuns de temática mais específica que as anteriores, algumas relacionadas a projetos do $\mathrm{CM}$ em parceria com outras organizações, outras ligados a temas atuais discutidos na imprensa global.

Na primeira semana de janeiro de 2015, por exemplo, criou-se uma coleção temática \#jesuischarlie, que reunia vários cartuns em 
homenagem aos cartunistas da revista Charlie Hebdo, mortos no atentado de 6 de janeiro. Pela profusão de cartuns relacionados à liberdade de expressão e críticos à censura a cartunistas, menos de uma semana após o atentado à revista de cartuns francesa Charlie Hebdo, percebe-se como o Cartoon Movement é de fato uma comunidade de profissionais que dividem valores em comum. Todos correram à defesa da liberdade de cartunistas frente ao ataque à revista satírica e morte de seus colegas cartunistas, independente de pressões editoriais ou comerciais. Esse foi o tema que dominou as seções Newsroom e Cartoons, com diversos trabalhos de cartunistas de todo o mundo, com diferentes estilos e opiniões, mas comentando sobre o mesmo assunto. Essa coleção complementa, de certa forma, outra, mais antiga, Cartoonists under pressure, que lida com o tema de liberdade de imprensa e de expressão e problemas de censura de que sofrem cartunistas de algumas partes do mundo, um tema caro à política editorial do CM. Com autores de diversos países sobre um mesmo tema, o CM, através de seus cartunistas, demonstra seu senso de comunidade - e as coleções temáticas são um bom exemplo disso.

Verificamos esse mesmo efeito, ainda que não relacionado à defesa liberdade de expressão em diversos momentos na coleta de dados. Comentando sobre os ataques de Israel a alvos civis na Palestina, em 2014, diversos cartunistas publicavam trabalhos de opiniões e estilos diferentes, muitas vezes diretamente respondendo a um cartum de opinião contrária publicado por outro profissional tendo, também, de lidar com os comentários, críticas e elogios, dos usuários. Assim, percebemos a característica de portfólio do CM, ou seja, como, da visão de veículos externos, o portal funciona como um grande brainstorming para a criação de cartuns. Essa enorme variedade será essencial para a manutenção financeira do site.

Os cartuns também são publicados pelo aplicativo da CM na AppStore. Pelo aplicativo, pode-se ter acesso a uma seção de votação nos cartuns, correspondente à Newsroom e outra com os cartuns publicados, correspondente à Cartoons. Também pode-se fazer 
comentários sobre os cartuns. A iniciativa de criação de um aplicativo mostra que o CM acompanha as tendências tecnológicas relacionadas à convergência tanto no que se refere ao campo do jornalismo quando ao dos quadrinhos. Reflete uma preocupação não só com a ampliação do público leitor, mas também com a manutenção de leitores que têm utilizado cada vez mais a internet a partir de tablets e smartphones, não tanto em computadores.

Comics (Figura 5) é a seção onde são publicadas as reportagens em quadrinhos. Há, inicialmente, uma lista com as 36 reportagens publicadas, organizadas de forma cronológica (a última aparece primeiro) ao longo de cinco webpages.

Figura 5: Seção Comics

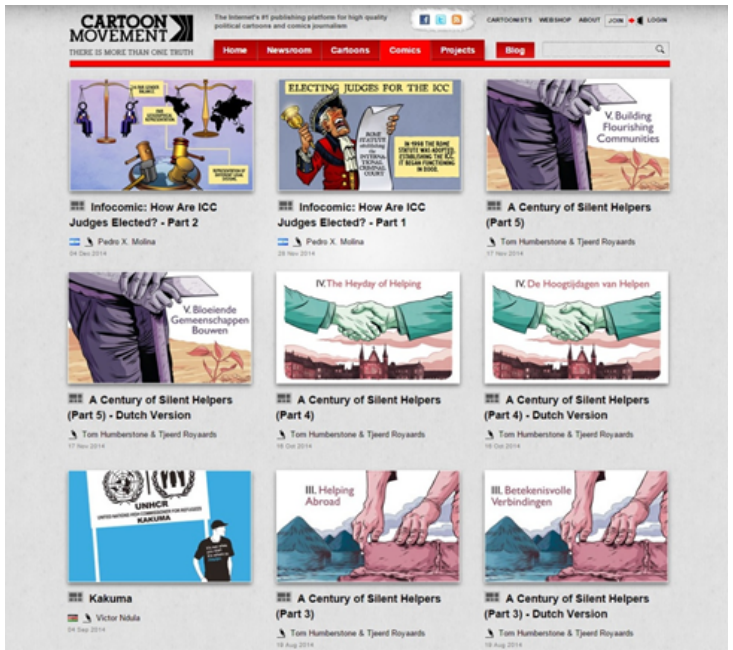

Fonte: http://www.cartoonmovement.com/

Por serem quadrinhos, e não imagens isoladas como os cartuns, todas as reportagens têm mais de uma página (hiperquadro) e cada um aparece em uma webpage própria. A webpage de cada reportagem a apresenta inteira, seja em uma plataforma de leitura própria ou na padrão do CM. Ou seja, a leitura de uma reportagem 
corresponde a um pageview para o site. Isso não é comum em webcomics, porque quanto mais pageviews, mais um site ganha de receita publicitária. Por isso, a estratégia preferencial, mesmo para webcomics serializados, é publicar cada hiperquadro em uma URL diferente, de forma que os pageviews sejam em igual número às páginas da história que cada usuário leu. Por outro lado, essa forma de publicação do CM possibilita que toda a reportagem seja lida de maneira fluida e natural, sem a necessidade de espera pelo carregamento de uma nova página da web a cada página lida da história. Dentro da plataforma de leitura padrão do CM, que funciona como um visualizador de imagens, todos os hiperquadros da reportagem são carregadas junto com a webpage, o que evita a espera e facilita a leitura. Nessa plataforma, a última página de cada reportagem tem um breve perfil sobre seu(s) autor(es), com dados sobre histórico profissional e links para blogs e outros trabalhos. Abaixo de cada reportagem há uma breve descrição ou sinopse de seu conteúdo, um link para o perfil do autor (novamente com o ícone da bandeira) e uma seção de comentários, onde usuários podem dar sua opinião.

A seção Projects (Figura 6) apresenta todos os atuais projetos colaborativos do Cartoon Movement com as mais diversas organizações. Esses projetos assumem várias formas, podendo ser apenas uma semana temática, em que os cartunistas são convidados a produzir conteúdo específico, até publicação de livro, lançamento de plataformas virtuais, organização de eventos, produção colaborativa de reportagens, ou ainda workshops, exposições e outras iniciativas sem fins lucrativos. 
Figura 6: Seção Projects

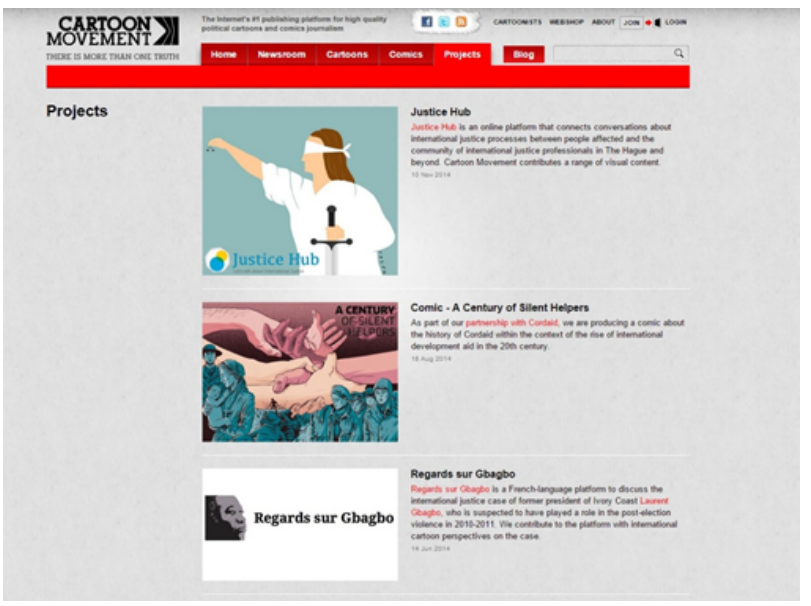

Fonte: http://www.cartoonmovement.com/

Algumas subseções da Newsroom são ambientes fixos para a publicação de conteúdo temático ligado a um projeto ou instituição. $\mathrm{O}$ mesmo acontece com diversas reportagens. A natureza dos projetos é muito variada, tratando de censura, liberdade, fome, alimentação, conflitos e busca pela paz, imigração ilegal, trabalho infantil, justiça internacional, educação, campanhas de solidariedade, ajuda a refugiados. Cada um deles é feito em parceria com organizações não-governamentais, instituições sociais e políticas, campanhas online, fundações de mídia alternativa e até quadrinistas individuais. Entre os parceiros, FAO (Food and Agriculture Organization, órgão das Nações Unidas que trabalha com temas ligados à alimentação e à produção de alimentos no mundo), JusticeHub (uma plataforma online para discussão de justiça internacional), Cordaid (uma organização de auxílio a pessoas em situação de extrema pobreza em diversos países), CAPS (evento que promove a discussão sobre sustentabilidade e inovação social), a União Africana de Direitos Humanos, entre vários outros. $\mathrm{O} \mathrm{CM}$ se insere, assim, em um cenário colaborativo, socialmente 
preocupado, politicamente engajado, ativista e alternativo à grande mídia.

A partir das seções $F A Q$ e Business (cujos links não estão presentes na Home, precisando ser acessados a partir da aba About) e da própria loja online do Cartoon Movement, percebemos que o site se mantém financeiramente de três formas, todas envolvendo a aquisição dos direitos de uso dos cartuns para posterior licenciamento para outras mídias e produtos. A primeira forma funciona de maneira similar à estrutura dos syndicates, própria do mercado de tirinhas estadunidense. O CM adquire os direitos de uso de um cartum e passa a servir de agente do cartunista, distribuindo esse conteúdo para veículos de todo o mundo, de forma exclusiva ou não. Isso beneficia os três participantes do processo: o cartunista fica com uma porcentagem da venda do cartum e consegue uma exposição maior do que teria publicando de forma impressa; os veículos têm acesso a conteúdo e a artistas de todo o mundo, com as mais diversas visões e estilos, o que não aconteceria com cartunistas empregados; e o CM, que liga um ao outro, fica com a outra parte dos lucros dessa venda, além de conseguir promover a discussão de temas e a colaboração de artistas e público. Nesse sentido, o site se configura de fato como uma plataforma de publicação, ligando o artista ao meio que vai publicar sua obra, e como uma comunidade de cartunistas que compartilham valores sociais e profissionais.

A segunda forma, também dependente dos direitos de uso, é sob demanda. Um veículo pode pedir um cartum específico sobre um tema para o site, que sugere a produção a seu time de quadrinistas. Esse modo funciona como um grande brainstorming, em que o veículo tem acesso a uma diversidade de conteúdo sobre o tema pedido, através de trabalhos submetidos por diferentes autores pelo mundo, e pode escolher o que lhe parecer melhor, também de forma exclusiva ou não. Se, anteriormente, verificamos esse brainstorming acontecendo de forma espontânea em resposta aos atentados ao Charlie Hebdo, este segundo modo de capitalização de conteúdo 
busca o mesmo efeito, mas a partir de um tema sugerido pelo veículo/cliente.

A terceira forma depende, até certo ponto, de cartuns que tragam uma crítica mais geral ou duradoura. Cartuns editoriais, como gênero surgido no jornalismo diário e que geralmente fazem comentários sobre acontecimentos atuais na mídia, tendem a ser mais efêmeros, tratando de notícias pontuais. Quando o cartum satiriza um aspecto mais geral da sociedade ou consegue uma proposta diferente, menos efêmera, para satirizar algo atual, o CM adquire seus direitos para estampá-lo em camisetas, vendidas pelo site da loja. Estampadas com cartuns fazendo críticas à guerra, à fome ou à injustiça, todos de trabalhos originados no CM. A webshop destaca ainda a possibilidade de se encomendar uma camiseta com qualquer cartum publicado no site, mesmo que não esteja em catálogo.

Assim, o CM não se sustenta, como a maioria dos sites na rede, com a ajuda de publicidade - logo, não há tanta preocupação em manter um público fiel ou em buscar um número de leitores cada vez maior - que muitas vezes pode comprometer o conteúdo publicado. Essa estratégia de licenciamento do site está vinculada à escolha da plataforma de leitura e seria desvantajosa para um sistema que dependesse dos pageviews de cada webpage/hiperquadro do quadrinho, que é o padrão para sites de webcomics. Afinal, não tendo um suporte financeiro publicitário, o número de acessos ao site não faz diferença: pode-se inserir todos os hiperquadros de uma história em uma mesma webpage, sem uso de links internos ou externos. $\mathrm{O}$ site não tem prejuízos e ao mesmo tempo possibilita ao público uma leitura mais fluida e agradável. É uma estratégia que também está ligada ao formato independente de publicação, comum no jornalismo em quadrinhos, que prioriza a liberdade financeira, autoral e criativa. 


\section{Considerações finais}

Explícita ou implicitamente, valores como a defesa da liberdade de imprensa, a preocupação com a cidadania, a promoção da paz e a luta contra injustiças sociais estão presentes no conteúdo das seções Comics, Cartoons, Projects, em cartums, reportagens e parcerias do site. A presença das verdades múltiplas do slogan There is more than one truth se concretiza, nos cartuns, não só através dos profissionais de mais de 80 países diferentes, mas também pelos usuários colaboradores (produsers), que sugerem temas e cartuns, por exemplo. O CM consegue, nas seções de cartuns, abranger uma quantidade muito grande de temáticas, estilos, visões e abordagens. Verificou-se diversas discussões, na forma de cartuns e comentários na respectiva seção, sobre os bombardeios de Israel a alvos civis na Palestina. Cartunistas defendiam um lado ou outro, justificavam ou criticavam as ações de cada lado e inclusive respondiam um cartum com outro de opinião contrária. Em temas mais polêmicos, esse tipo de reação é frequente no site - pois os editores não controlam o voto dos usuários, que podem acabar escolhendo cartuns de orientações diferentes. Tendo votos suficientes, o cartum passa da Newsroom para Cartoons, independente da escolha do editor, e de lá pode ser adquirido por veículos de todo o mundo independente da preferência deles. Podem também ir pra essa seção apenas pela escolha dos editores, independente dos votos dos usuários.

Essas características também ficam evidentes na análise da seção Projects. A seção mais ativista do $\mathrm{CM}$ conta com iniciativas em vários países sobre diferentes temas. As organizações que colaboram em cada projeto também são de diversas nacionalidades e cada um tem objetivos diferentes: chamar a atenção sobre um tema, angariar doações para uma causa, dar voz a pessoas envolvidas em conflitos ou em situações desfavoráveis, promover discussões sobre assuntos em pauta na grande mídia ou fora dela. Os parceiros do site 
vão de órgãos da ONU a portais independentes de notícia, de ONGs de assistência humanitária a órgãos de promoção dos direitos humanos na África, além de entidades promotoras da liberdade de imprensa e luta contra censura. A abertura à diferença de opiniões é o que guia também a maneira como o CM lida com seus leitores todas as seções têm possibilidade de comentários de usuários, assim como a webpage de cada cartum ou reportagem, e há sempre uma preocupação em receber feedback, mesmo nas mídias sociais externas ao site, como Facebook ou Twitter. O CM quer não só o compartilhamento de seu conteúdo nesses sites, mas também a opinião de seus leitores, sejam boas ou ruins - e é freqüente aparecerem críticas no feed automático de comentários e tweets presentes na Home. Também na existência de um aplicativo para dispositivos móveis vemos essa preocupação: o CM busca opinião e comentários dos usuários onde quer que eles estejam, estando junto de cada leitor potencialmente o tempo inteiro.

Percebe-se como a estrutura comercial libera o conteúdo editorial do site para seguir mais de perto seus valores institucionais. Ao tirar tanto peso do pólo comercial (TRAQUINA, 2005), o pólo ideológico pode se fortalecer. Todos os valores do campo jornalístico (TRAQUINA, 2005) estão presentes na estrutura de produção do conteúdo do $\mathrm{CM}$ : liberdade, independência e autonomia, credibilidade, verdade e objetividade. A defesa da liberdade é um dos pilares institucionais do site e está presente em coletâneas de cartuns, projetos e reportagens. Autonomia e independência surgem do modelo de manutenção financeira, que tira grande parte do peso do pólo comercial. A credibilidade aparece em diversos níveis: a ligação do site com o VJ Movement, uma comunidade internacional e independente de jornalistas; as diversas parcerias com outras entidades e organizações, que legitimam, com sua autoridade, o conteúdo ali publicado; os processos de seleção e transformação na produção das reportagens, nas conversas entre jornalistas-quadrinistas e os editores do CM; toda a estrutura do site, 
que se aproxima visualmente de um portal de notícias e não de um site de webcomics; o financiamento próprio, que possibilita a independência e autonomia de publicidade e legitima seu conteúdo; o nome e currículo dos jornalistas que produzem as reportagens. A noção de verdade do CM, pelo slogan, é a de múltiplas verdades: isso se apresenta na multiplicidade de vozes que têm espaço no site, representando diversas regiões e visões de mundo alternativas à grande mídia. Além disso, os diversos projetos e parcerias promovidos pelo site facilitam a ligação entre autores, fontes, produtores e leitores. Várias reportagens e grande parte das coleções temáticas de cartuns são originados de um projeto ou parceria, o que aumenta a visibilidade e dá mais credibilidade ao conteúdo relatado. É também por parcerias que são publicadas versões impressas a partir das reportagens do site: além da graphic novel Army of God, Haiti: tents beyond tents também tem uma versão impressa (tendo a versão digital sido republicada, na época, por diversos sites de grandes jornais).

Assim, a produção colaborativa e a representação de diferentes vozes dentro do Cartoon Movement tanto na seção de cartuns quanto na de reportagens em quadrinhos só é possível graças à independência editorial alcançada com o abandono da forma de manutenção financeira tradicional dos webcomics e do jornalismo.

\section{Referências}

BARBOSA, S. Modelo JDBD e o ciberjornalismo de quarta geração. Artigo apresentado no GT 7 - Cibercultura y

Tendencias de la Prensa en Internet, do III Congreso Internacional de Periodismo em la Red. Foro Web 2.0: Blogs, Wikis, Redes Sociales y e-Participación, na Facultad de Periodismo da Universidad Complutense de Madrid, 2008. 
BARBOSA, S; Silva, F. F.; Nogueira, L; Almeida, Y. A atuação jornalística em plataformas móveis. Estudo sobre produtos autóctones e a mudança no estatuto do jornalista. Brazilian Journalism Research. Vol. 9, N.2, 2013. Recuperado em 20/03/2015 de http://bjr.sbpjor.org.br/bjr/article/viewFile/549/489.

KOGEL, D. Rethinking Webcomics: Webcomics as a Screen Based Medium. Dissertação de Mestrado. (2013). Department of Art and Culture Studies/Jyväskylän University, Jyväskylä.

Recuperado em 20/03/2015 de https://jyx.jyu.fi/dspace/bitstream/handle/123456789/40712/ URN:NBN:fi:jyu-201301161066.pdf.

MALLET, T. Os quadrinhos e a internet: aspectos e experiências híbridas. Dissertação de mestrado. (2009). PPGA/UFMG, Belo Horizonte.

MIELNICZUK, L. Jornalismo na web: uma contribuição para o estudo do formato da notícia na escrita hipertextual. Tese de doutorado. (2003). PósCOM, UFBA, Salvador. Recuperado em 20/03/2015 de http://poscom.tempsite.ws/wp-content/uploads/2011/05/Luciana-Mi elniczuk.pdf.

PALACIOS, M. Jornalismo On-line, informação e memória: apontamentos para debate. Comunicação apresentada nas Jornadas de Jornalismo On-line, Universidade da Beira do Interior, Portugal, 2002.

PALACIOS, M; Machado, E. Modelos de jornalismo digital. Salvador: Salamandra, 2005. 


\section{PAREDES, D. B. Características y evolución Del webcómic en}

Estados Unidos y en España. Dissertação de mestrado. (2013)

Facultat de Bellrs Arts/Universidade Politécinca, Valencia.

ROMAGUERA, G. E. Piecing the parts: an analysis of narrative strategies and textual elements in microserialized webcomics. Dissertação de mestrado. (2010). Universidade de Puerto Rico, Mayaguez. Cedido pelo autor.

SANTOS, R. Webcomics Malvados: tecnologia e interação nos quadrinhos de André Dahmer. Dissertação de mestrado. (2010). PPFTec/UTFPR, Curitiba. Cedido pelo autor.

STEENSEN, S. (2010). Online journalism and the promises of new technology: a critical review and look ahead. Recuperado em 20/03/2015 de https://oda.hio.no/jspui/bitstream/10642/601/2/512648post.pdf.

TRAQUINA, N. Teorias do Jornalismo: Volume II. Florianópolis: Insular, 2005. 